\title{
The Prevalence and Therapeutic Effect of Constipation in Pediatric Overactive Bladder
}

\author{
Ji Hyun Kim, Ji Hyun Lee, A Young Jung ${ }^{1}$, Jung Won Lee \\ Departments of Pediatrics and ${ }^{1}$ Radiology, Hallym University Kangnam Sacred Heart Hospital, Seoul, Korea
}

Purpose: Overactive bladder (OAB) is a manifestation of urgency, regardless of urge incontinence, due to involuntary bladder contraction during the storage period. There is a close association between constipation and $\mathrm{OAB}$, but constipation cannot be readily diagnosed. The aims of this study were to evaluate the prevalence of constipation in $\mathrm{OAB}$ and the consequent therapeutic effects according to the diagnostic criteria for constipation.

Methods: We collected clinical data from 40 children (mean age, $71 \pm 22$ months) with chief complaints of urgency, frequency, and incontinence. A voiding questionnaire and a 2-day voiding diary were collected, and urinalysis, the Bristol stool scale, and plain abdominal radiography were performed. Constipation was defined as conditions satisfying at least one of the following criteria: Rome III diagnostic criteria, Bristol stool scale types I/II, or a Leech score higher than 8 points as determined by plain radiography. Lower urinary tract symptoms, defecation symptoms, and the bladder volume of patients were examined, and the therapeutic outcomes by constipation diagnostic criteria were evaluated.

Results: Of the $40 \mathrm{OAB}$ patients, 25 had constipation. Among them, 6 had reduced functional bladder capacity $(24 \% ; \mathrm{P}>0.05)$. Regarding treatment, in patients who satisfied only one diagnostic criterion, the symptoms improved in $76.9 \%, 76.9 \%$, and $69.6 \%$ of patients meeting the Rome III criteria, Bristol stool scale, and Leech score, respectively $(\mathrm{P}<0.05)$. Among the 8 patients satisfying all three criteria, $75 \%$ responded to treatment $(\mathrm{P}<0.05)$.

Conclusions: The prevalence of constipation in OAB is high. Constipated patients recruited by use of the Rome III criteria, Bristol scale, and Leech score alone and together showed similar outcomes on OAB improvement after the treatment of constipation, which implies that each criterion has the same strength and can be applied comprehensively and generally.

Keywords: Overactive urinary bladder; Pediatrics; Constipation

\section{INTRODUCTION}

Overactive bladder $(\mathrm{OAB})$ is a voiding dysfunction that commonly occurs in children. It is regarded as to be related to the detrusor contraction during bladder filling that occurs involuntarily or induced contraction that cannot be controlled. The hallmark of $\mathrm{OAB}$ is urgency regardless of the presence or absence of urge incontinence. It is frequently associated with daytime frequency and nocturia. Previous studies have shown that $\mathrm{OAB}$ is closely associated with constipation, and voiding symp- toms are improved only by treatment of constipation. Thus, at the time of diagnosis, constipation should always be considered [1-4]. However, the diagnosis of constipation is difficult because it depends on simple description by guardians and various defecation symptoms reported by the children themselves. Although it can be diagnosed by various methods, it remains difficult to diagnose constipation in clinics.

The aims of this study were to examine the prevalence of constipation in children with OAB by applying the Rome III criteria, the Bristol stool scale, and the Leech method, which
Corresponding author: Jung Won Lee

Department of Pediatrics, Hallym University Kangnam Sacred Heart Hospital,

948-1 Daerim 1-dong, Yeongdeungpo-gu, Seoul 150-950, Korea

Tel: +82-2-829-5142 / Fax: +82-2-829-5358

E-mail: happymaniajw@hanmail.net

Submitted: September 21, 2011 / Accepted after revision: December 7, 2011
This is an Open Access article distributed under the terms of the Creative Commons Attribution Non-Commercial License (http://creativecommons.org/licenses/by-nc/3.0/) which permits unrestricted non-commercial use, distribution, and reproduction in any medium, provided the original work is properly cited. 
uses abdominal radiography to determine constipation, and to examine the therapeutic outcomes by each diagnostic criterion.

\section{MATERIALS AND METHODS}

This study included 40 children aged between 4 and 9 years who visited the Department of Pediatrics, Hallym University Gangnam Sacred Heart Hospital, between September 2008 and February 2010 with chief complaints of urgency, frequency, and incontinence and who were subsequently diagnosed with OAB. To exclude urinary tract infection (UTI), each patient underwent urinalysis. Patients with congenital urinary tract conditions and neurological problems were excluded. A voiding questionnaire and a 2-day voiding diary, including the defecation habit and Bristol stool scale, were given to patients, and plain abdominal radiographs were taken. The Rome III diagnostic criteria have been used most widely for the diagnosis of constipation, and include two or more of the following categories: two or fewer defecation episodes per week, painful or hard stool, retentive posturing or excessive volitional stool retention, large fecal mass in the rectum, at least 1 episode of fecal incontinence per week, and large-diameter stools that may obstruct the toilet. The Bristol stool form scale evaluates constipation by stool cohesion and surface cracking. Patients with stools corresponding to type I (small, hard, and lump patterns that look like goat feces) and type II (several hard lumps that look like goat feces and form clusters) are considered constipated [5]. The Leech method diagnoses constipation by dividing plain abdominal radiographs into three compartments: the proximal area of the ascending colon and the transverse colon, the distal area of the transverse colon and the descending colon, and the colorectal area. The level of stool filling is scored between 0 and 5 points, and patients with a total score higher than 8 points are diagnosed with constipation [6].

In this study, the scores were determined by a radiologist and a pediatrician independently, and their average scores were used. Patients who satisfied one or more of the above diagnostic criteria were diagnosed with constipation. On the basis of the voiding diary, lower urinary tract symptoms, defecation symptoms, and bladder volume were examined. The expected bladder volume was calculated by the Hjalmas formula: bladder volume $(\mathrm{mL})=(\mathrm{age}+1) \times 30$ [7]. The maximal voided volume was the maximal volume of the recorded voided volume in the voiding diary, and it was a surrogate to the functional bladder capacity. If the functional bladder capacity was less than $65 \%$ of the expected bladder capacity, it was considered a reduction of bladder capacity [8].

Good therapeutic effect was defined as improved lower urinary tract symptoms according to a follow-up voiding diary after 3 months. Therapeutic effects according to the constipation diagnostic criteria were evaluated.

We used the SAS ver. 9.0 (SAS Institute Inc, Cary, NC, USA). The chi-square test and t-test were used to compare the therapeutic effects of constipation treatment on the alleviation of OAB. P-values of less than 0.05 were considered to be statistically significant.

\section{RESULTS}

The patients comprised 16 boys (40.0\%) and 24 girls (60.0\%). The patients' mean age was $6.4 \pm 1.9$ years (range, 4 to 9 years). Of patients who experienced lower urinary tract symptoms, 37 (92.5\%) had urgency, 32 (80\%) had frequency, 15 (37.5\%) had urge incontinence, 22 (55\%) had daytime incontinence, 8 (20\%) had enuresis, and 6 (15\%) had nocturia (Table 1). Constipation symptoms manifested as fecal incontinence $(12.5 \%)$, two or fewer defecation episodes per week (7.5\%), large-diameter stools that may obstruct the toilet (22.5\%), painful or hard stools (42.5\%), retentive posturing or excessive volitional stool retention (35.0\%), abdominal pain (5.0\%), and palpable fecal mass in the rectum $(2.5 \%)$.

When OAB risk factors [7] were examined, enuresis (20.0\%), fecal incontinence (12.5\%), constipation that satisfied the Rome III diagnostic criteria (45.0\%), Bristol stool scale type 1 or 2 (30.0\%), Leech score higher than 8 points (57.5\%), and history of UTI (15.0\%) were found. Among $40 \mathrm{OAB}$ patients, 25 (62.5\%) had constipation. Of them, 6 (24\%) patients experienced re-

Table 1. Incidence of lower urinary tract symptoms in $\mathrm{OAB}$

\begin{tabular}{lr}
\hline LUTS & Value \\
\hline Urgency & $37(92.5)$ \\
Frequency & $32(80.0)$ \\
Urge incontinence & $15(37.5)$ \\
Daytime incontinence & $22(55.0)$ \\
Enuresis & $8(20.0)$ \\
Holding maneuver & $15(37.5)$ \\
Nocturia & $6(15.0)$ \\
\hline
\end{tabular}

Values are presented as number (\%).

LUTS, Lower urinary tract symptom; OAB, Overactive bladder. 
Table 2. Bladder capacity in overactive bladder (OAB)

\begin{tabular}{lcc}
\hline \multirow{2}{*}{ Bladder capacity } & \multicolumn{2}{c}{ OAB } \\
\cline { 2 - 3 } & Constipation $(-)$ & Constipation $(+)$ \\
\hline Normal & $11(73.3)$ & $19(76.0)$ \\
Decreased & $4(27.7)$ & $\left.6(24.0)^{\mathrm{a}}\right)$ \\
Total & $15(100)$ & $25(100)$ \\
\hline
\end{tabular}

Values are presented as number (\%).

a) $\mathrm{P}>0.05$ vs. constipation (-).

Table 3. Treatment modality of overactive bladder

\begin{tabular}{lc}
\hline Variable & Value \\
\hline Anticholinergics & $16(40.0)$ \\
Oxybutynin (detropan) & $1(2.5)$ \\
Tolterodine (detrusitol) & $10(25.0)$ \\
Propiverine (BUP) & $5(12.5)$ \\
Osmotic Laxatives & $24(60.0)$ \\
Lactulose (duphalac) & $18(45.0)$ \\
PEG 3350 (forlax) & $6(15.0)$ \\
Total & $40(100)$ \\
\hline
\end{tabular}

Values are presented as number (\%).

duced functional bladder capacity, but in comparison with the bladder capacity of $\mathrm{OAB}$ patients without constipation, the difference was not significant $(\mathrm{P}>0.05)$ (Table 2).

As for OAB therapy, 16 patients (40\%) were treated with anticholinergic agents, and 24 (60\%) were treated with osmotic laxatives (Table 3). Of $25 \mathrm{OAB}$ patients with associated constipation, good outcome and poor outcome groups were compared among subgroups satisfying one or more of the constipation diagnostic criteria. Eight patients satisfied all 3 diagnostic criteria and 6 of the 8 (75\%) experienced improved OAB by treatment with osmotic laxatives only $(\mathrm{P}=0.009)$. In patients who satisfied only one diagnostic criteria, the good outcome groups were $76.9 \%$ (10/13), 76.9\% (10/13), and 69.6\% (16/23) of the patients in the Rome III criteria $(\mathrm{P}<0.001)$, Bristol stool scale $(\mathrm{P}=0.004)$, and Leech score $(\mathrm{P}<0.001)$ subgroups, respectively (Table 4 ).

\section{DISCUSSION}

$\mathrm{OAB}$ is a manifestation of urgency, regardless of urge incontinence, due to involuntary bladder contraction during the storage period. It is also known as hypersensitive bladder syndrome, urgency syndrome, overactive bladder syndrome, persistent in-
Table 4. Therapeutic effects by diagnosis criteria of constipation in overactive bladder

\begin{tabular}{lrrr}
\hline Variable & $\begin{array}{c}\text { Good } \\
\text { outcome }\end{array}$ & $\begin{array}{c}\text { Poor } \\
\text { outcome }\end{array}$ & P-value \\
\hline Rome III $(\mathrm{n}=13)$ & $10(76.9)$ & $3(23.1)$ & $<0.001$ \\
Bristol scale $(\mathrm{n}=13)$ & $10(76.9)$ & $3(23.1)$ & 0.004 \\
Leech score $(\mathrm{n}=23)$ & $16(69.6)$ & $7(30.4)$ & $<0.001$ \\
Rome+Bristol $(\mathrm{n}=12)$ & $10(83.3)$ & $2(16.7)$ & 0.001 \\
$\begin{array}{l}\text { Bristol+Leech }(\mathrm{n}=11) \\
\text { Leech+Rome }(\mathrm{n}=16)\end{array}$ & $8(72.7)$ & $3(27.3)$ & 0.030 \\
$\begin{array}{l}\text { Rome+Bristol+Leech } \\
(\mathrm{n}=8)\end{array}$ & $6(75.0)$ & $2(25.0)$ & 0.009 \\
\hline
\end{tabular}

Values are presented as number (\%).

fant bladder, and hypertonicity of the detrusor [9]. At the 2002 International Incontinence Conference, $\mathrm{OAB}$ was defined as urinary urgency regardless of urge incontinence, and it is associated with daytime and nighttime frequency in most cases. Nonetheless, it is not required to prove detrusor overactivity by urodynamic study [8].

In a prospective multi-center study performed in 16 Korean medical school hospitals in 2006, the risk factors for OAB were examined. Enuresis, constipation, fecal incontinence, UTI history, and delayed toilet training were considered risk factors associated with $\mathrm{OAB}[10]$. In our study of $\mathrm{OAB}$, frequency and urgency occurred in 80 and $92.5 \%$ of patients, respectively, and it was the most common voiding symptom. Of the OAB risk factors, $45.0 \%$ of patients satisfied the Rome III diagnostic criteria, $30.0 \%$ corresponded to the Bristol stool scale type 1 or 2, and $57.5 \%$ scored higher than 8 points on the Leech score.

It is well known that $\mathrm{OAB}$ is closely associated with constipation. Furthermore, the results of studies on voiding symptoms improved only by treating constipation support this [2,9,10-15]. It has been shown that constipation induces bladder dysfunction by the following mechanism: when the rectum is filled with stools, stretch receptors are stimulated and transmitted to the brain, which induces temporary involuntary contraction of the external anal sphincter and the puborectalis muscles. If defecation is not feasible, the muscles contract voluntarily. As the process becomes repeated, the feces accumulate within the rectum, and this shortens the bladder contraction period and ultimately bladder activity is abolished [16]. Another hypothesis suggests that when the rectum is distended, it compresses the adjacent bladder and decreases the functional bladder capacity [9]. Another hypothesis suggests that if stretch receptors are stimulated 
because of fecal accumulation, diverse patterns of bladder contraction occur and induce bladder instability [2,4]. Our study showed no difference in functional bladder capacity in patients with $\mathrm{OAB}$ with and without constipation.

Loening-Baucke et al. [1] reported that in 234 children with chronic constipation, the rate of association between incontinence and UTI was as follows: $29 \%$ for daytime incontinence, $34 \%$ for nighttime incontinence, and $11 \%$ for a history of UTI. With successful treatment of constipation, improvement was seen in $89 \%$ of patients with daytime incontinence, $63 \%$ of patients with nighttime incontinence, and $100 \%$ of patients with recurrent UTI without anatomical abnormalities.

However, the diagnosis of constipation in children differs from that in adults. Diagnosis in children is dependent on the description of guardians, and it remains a challenge clinically. The Rome II diagnostic criteria, which focus on symptoms, have been used from 1999, and the revised Rome III diagnostic criteria were suggested in 2006 [17].

Other commonly used methods such as the Bristol stool form scale [18] and the Leech method assess the level of stools within the intestine by plain radiography [6,19]. Additional methods include anorectal manometry, defecography, electromyography, and rectal biopsy.

In our study, children who satisfied more than one of three diagnostic methods (Rome III diagnostic criteria, Bristol stool form scale, and Leech method) were diagnosed as having constipation. Of the $40 \mathrm{OAB}$ patients, 25 had associated constipation (62.5\%). Among the $25 \mathrm{OAB}$ patients with constipation, 8 patients satisfied all three diagnostic criteria, and in 6 of the 8 patients (75\%), OAB symptoms improved by treatment with osmotic laxatives. In children who satisfied only one diagnostic criterion, therapeutic effects were seen in $76.9 \%, 76.9 \%$, and $69.6 \%$, respectively.

Our findings suggest that constipation should always be considered in the diagnosis of $\mathrm{OAB}$. Also, together with the subjective Rome III diagnostic criteria, the Bristol stool form scale and the Leech method are noninvasive, economical, simple, and objective methods for the diagnosis of constipation and can be generally applied.

\section{CONFLICT OF INTEREST}

No potential conflict of interest relevant to this article was reported.

\section{REFERENCES}

1. Loening-Baucke V. Urinary incontinence and urinary tract infection and their resolution with treatment of chronic constipation of childhood. Pediatrics 1997;100(2 Pt 1):228-32.

2. Chase JW, Homsy Y, Siggaard C, Sit F, Bower WF. Functional constipation in children. J Urol 2004;171(6 Pt 2):2641-3.

3. De Wachter S, Wyndaele JJ. Impact of rectal distention on the results of evaluations of lower urinary tract sensation. J Urol 2003;169: 1392-4.

4. O’Regan S, Yazbeck S, Hamberger B, Schick E. Constipation a commonly unrecognized cause of enuresis. Am J Dis Child 1986;140: 260-1.

5. Lewis SJ, Heaton KW. Stool form scale as a useful guide to intestinal transit time. Scand J Gastroenterol 1997;32:920-4.

6. van den Bosch M, Graafmans D, Nievelstein R, Beek E. Systematic assessment of constipation on plain abdominal radiographs in children. Pediatr Radiol 2006;36:224-6.

7. Hjälmås K. Micturition in infants and children with normal lower urinary tract. A urodynamic study. Scand J Urol Nephrol 1976;Suppl 37:1-106.

8. Nevéus T, von Gontard A, Hoebeke P, Hjälmås K, Bauer S, Bower W, et al. The standardization of terminology of lower urinary tract function in children and adolescents: report from the Standardisation Committee of the International Children's Continence Society. J Urol 2006;176:314-24.

9. Franco I. Overactive bladder in children. Part 1: Pathophysiology. J Urol 2007;178(3 Pt 1):761-8.

10. Chung JM, Lee SD, Kang DI, Kwon DD, Kim KS, Kim SY, et al. Prevalence and associated factors of overactive bladder in Korean children 5-13 years old: a nationwide multicenter study. Urology 2009;73:63-7.

11. Bannister JJ, Lawrence WT, Smith A, Thomas DG, Read NW. Urological abnormalities in young women with severe constipation. Gut 1988;29:17-20.

12. Cayan S, Doruk E, Bozlu M, Duce MN, Ulusoy E, Akbay E. The assessment of constipation in monosymptomatic primary nocturnal enuresis. Int Urol Nephrol 2001;33:513-6.

13. Kim KH, Kim YS. Common urinary symptoms in outpatient clinic: voiding dysfunction in children. Korean J Pediatr 2005;48:575-9.

14. Kajiwara M, Inoue K, Kato M, Usui A, Kurihara M, Usui T. Nocturnal enuresis and overactive bladder in children: an epidemiological study. Int J Urol 2006;13:36-41.

15. Kim A, Lee H, Hong CH, Han SW. The significance of the parents' description of constipation in pediatric voiding dysfunction. Kore- 
an J Urol 2008;49:439-42.

16. Miyazato M, Sugaya K, Nishijima S, Ashitomi K, Ohyama C, Ogawa Y. Rectal distention inhibits bladder activity via glycinergic and GABAergic mechanisms in rats. J Urol 2004;171:1353-6.

17. Rasquin A, Di Lorenzo C, Forbes D, Guiraldes E, Hyams JS, Staiano A, et al. Childhood functional gastrointestinal disorders: child/ adolescent. Gastroenterology 2006;130:1527-37.
18. Riegler G, Esposito I. Bristol scale stool form. A still valid help in medical practice and clinical research. Tech Coloproctol 2001;5: 163-4.

19. Koh H, Lee MJ, Kim MJ, Shin JI, Chung KS. Simple diagnostic approach to childhood fecal retention using the Leech score and Bristol stool form scale in medical practice. J Gastroenterol Hepatol 2010;25:334-8. 